\title{
Níveis de suplementação sobre as características quantitativas da carcaça e composição tecidual do pernil de caprinos mestiços terminados na caatinga ${ }^{1}$
}

\author{
Levels of supplementation on quantitative carcass aspects and leg tissue composition of \\ crossbred goats finish on caatinga
}

\author{
SILVA, Daniel Cézar da ${ }^{2 *}$; GUIM, Adriana ${ }^{3}$; SANTOS, Gladston Rafael de Arruda ${ }^{4}$; \\ MESQUITA, Fernando Lucas Torres de ${ }^{5}$; MORAIS, Nathalia Andressa Pereira de ${ }^{3}$; \\ URBANO, Stela Antas ${ }^{3}$; MOREIRA FILHO, Miguel Arcanjo ${ }^{6}$; LAFAYETTE, \\ Elizabeth Almeida ${ }^{7}$
}

\footnotetext{
${ }^{1}$ Pesquisa de Doutorado financiada pela FACEPE.

${ }^{2}$ Instituto Federal da Paraíba, Unidade São Gonçalo, Sousa, Paraíba, Brasil.

${ }^{3}$ Universidade Federal Rural de Pernambuco, Departamento de Zootecnia, Recife, Pernambuco, Brasil.

${ }^{4}$ Universidade Federal de Sergipe, Departamento de Zootecnia, Aracaju, Sergipe, Brasil.

${ }^{5}$ Instituto Agronômico de Pernambuco, Sertânia, Pernambuco, Brasil.

${ }^{6}$ Universidade Federal do Piauí, Centro de Ciências Agrárias, Departamento de Zootecnia, Teresina, Piauí, Brasil.

${ }^{7}$ Universidade Federal de Pernambuco, Departamento de Antibióticos, Recife, Pernambuco, Brasil.

*Endereço para correspondência: danielcezar.s@ig.com.br
}

\section{RESUMO}

Avaliou-se o efeito da suplementação alimentar nos níveis, $0 ; 0,4 ; 0,8$ e 1,2\% do peso corporal (PC), sobre as características quantitativas da carcaça e composição tecidual do pernil de caprinos mestiços terminados em pastagem de caatinga. Utilizaram-se 32 caprinos machos castrados, mestiços da raça Anglonubiana, com oito meses de idade e peso corporal de $18 \pm 2,5 \mathrm{~kg}$, distribuídos em delineamento de blocos casualizados, que foram mantidos em área de 37 hectares de pastagem de caatinga das $7 \mathrm{~h}$ às $16 \mathrm{~h}$. O peso corporal sem jejum, peso corporal final, peso de carcaça quente e fria, peso de corpo vazio, rendimentos de carcaça quente e fria foram influenciados $(\mathrm{P}<0,05)$ pelos níveis de suplementação alimentar, com acréscimos lineares de, 3,50; 2,59; 1,69; 1,76; $3,39 \mathrm{~kg} ; 2,42$ e $2,44 \%$, respectivamente. Os pesos dos cortes comerciais foram influenciados $(\mathrm{P}<0,05)$ pelos níveis de suplementação alimentar, a exceção do peso do pescoço. O rendimento dos cortes não foi influenciado $(\mathrm{P}>0,05 \%)$ pela suplementação, com médias, 10,$17 ; 21,19 ; 16,23 ; 11,02 ; 7,30$ e $34,08 \%$, para o pescoço, paleta, costilhar, serrote, lombo e pernil, respectivamente. A composição tecidual em peso absoluto do pernil foi influenciada
$(\mathrm{P}<0,05)$ pela suplementação alimentar, com incremento de 293,59; 212,04; 28,29 e 53,82g, por unidade percentual do nível de suplementação, para o pernil inteiro, músculo total, gordura total e osso, respectivamente. A suplementação alimentar eleva os parâmetros quantitativos da carcaça, associado a incrementos no tecido muscular, gordura total e ossos do pernil, recomendando-se emprego de $1,2 \%$ PC, com vistas a melhor acabamento para comercialização.

Palavras-chave: estratégia alimentar, pastagem nativa, rendimento de carcaça, tecido muscular

\section{SUMMARY}

It was evaluated the effect of supplementation feeding levels $(0 ; 0.4 ; 0.8$; and $1.2 \%$ of body weight $\mathrm{BW}$ ) on carcass aspects and leg tissue composition of crossbred goats finish on caatinga pasture. Were used 32 goats crossbred Anglonubiana, with eight months of age and $18 \pm 2.5$ kilogram of $\mathrm{BW}$, organized in randomized blocks, which were kept in 37 hectares of caatinga pasture, where they remained from $07 \mathrm{~h}$ to $16 \mathrm{~h}$. Fasted live weigh, finish body weight, hot and cold carcass weight, 
empty body weight, hot and cold carcass yields, were influenced $(\mathrm{P}<.05)$ by supplementation feeding, raise of $3.50 ; 2.59 ; 1.69 ; 1.76 ; 3.39$ kilogram, and $2.43 ; 2.44 \%$, respectively. Retail cuts weight were influenced $(\mathrm{P}<.05)$ by supplementation, except neck weight. The cuts yield was not affected (P>.05) by supplementation with means, 10.17; 21.19; $16.23 ; 11.02 ; 7.30$ and $34.08 \%$, for neck, shoulder, ribs, brisket, loin and leg, respectively. Absolute weight of leg tissue composition was influenced $(\mathrm{P}<.05)$ by supplementation, with increase of, 293.59, 212.04, 28.29 and 53.82g, per unit percentage of supplementation, for total leg, total muscle, total fat and bone, respectively. Supplementation feeding increase carcass aspects, associated with increases in leg muscle tissue, fat and bones, recommending use of $1.2 \%$ of $\mathrm{BW}$, to better finish for sale.

Keywords: carcass yield, feeding strategy, muscle tissue, native pasture

\section{INTRODUÇÃO}

A população de caprinos da região Nordeste do Brasil é estimada em 8,5 milhões cabeças, correspondendo a aproximadamente $91 \%$ do efetivo nacional (IBGE/PPM, 2011), com maior concentração nas áreas áridas e semiáridas, onde desempenha importante função social para pequenos produtores rurais.

No entanto, os produtos de origem caprina transcenderam a barreia rural, e de acordo com Lisboa et al. (2010), entre as espécies de ruminantes criados para produção de carne, pequenos ruminantes são os que apresentam menor intervalo entre o nascimento e o abate, sendo a carne considerada uma iguaria, apreciada, com possibilidade de valorização superior às demais carnes.

Apesar deste viés econômico, os aspectos de qualidade da carne caprina da região Nordeste ainda estão aquém da real necessidade, pois esta é proveniente de animais de má conformação, fato que pode se atribuído ao manejo alimentar, predominante a base de vegetação nativa da caatinga.

$\mathrm{O}$ conhecimento do rendimento $\mathrm{e}$ composição tecidual da carcaça possibilita avaliação dos aspectos quantitativos da carne, o que pode melhorar sua comercialização, pois, cortes com boa conformação tecidual possuem maior valor comercial (MONTE et al., 2007).

Diante do cenário de consumidores cada vez mais exigentes, torna-se necessário a avaliação de grupos genéticos predominantes na região Nordeste, como os mestiços. Associado a este fator, deve-se avaliar o efeito da nutrição sobre a qualidade da carne, sobretudo nas regiões semiáridas.

Neste sentido, a suplementação alimentar apresenta-se como alternativa prática, por apresentar como foco principal a compensação da carência e/ou complementação da disponibilidade de matéria seca potencialmente digestível, associada à ideia de correção de nutrientes limitantes.

Esta estratégia alimentar é indispensável nos sistemas de produção inseridos no semiárido nordestino, principalmente aqueles que apresentam como base alimentar para os rebanhos, o pasto de caatinga, que apresenta flutuação anual da qualidade e quantidade de forragem disponível para o pastejo. Porem, os efeitos do uso desta estratégia alimentar sobre as características quantitativas da carne caprina são pouco conhecidos, o que orienta para necessidade de tais avaliações.

O objetivo desta pesquisa foi avaliar o efeito da suplementação alimentar sobre as características quantitativas e composição tecidual do pernil de caprinos mestiços terminados em pastagem de caatinga. 


\section{MATERIAL E MÉTODOS}

A pesquisa foi conduzida no período de agosto a dezembro de 2009, na Estação Experimental de Sertânia, pertencente ao Instituto Agronômico de Pernambuco (IPA), localizada a latitude $08^{\circ} 04^{\prime} 25^{\prime \prime}$ sul e a longitude $37^{\circ} 15{ }^{\prime} 52^{\prime \prime}$ oeste, na microrregião do Sertão do Moxotó, em ecossistema de caatinga, clima do tipo BShW, semiárido, com duas estações distintas, chuvosa e seca, apresentando temperatura média para o período de avaliação de $25,1^{\circ} \mathrm{C}$, e pluviosidade acumulada para o período de 71,05mm (LAMEPE, 2011).

Avaliou-se o efeito dos níveis de suplementação alimentar energéticoproteica, $0 ; 0,4 ; 0,8$ e $1,2 \%$ do peso corporal (\%PC), com base na matéria seca, que foram estipulados levando-se em consideração os resultados da composição química e degradabilidade in situ obtidos por Santos et al. (2009), na mesma área experimental de condução desta pesquisa.

O suplemento alimentar foi composto por palma miúda (Nopalea cochenillifera (L.) S.D.) processada em máquina picadora de palma, e concentrado formulado de acordo com as exigências nutricionais preconizadas pelo NRC (2007) para atender ganho médio diário mínimo de $50 \mathrm{~g}$ (Tabela 1).

Procedeu-se a pesquisa com 32 caprinos machos castrados, mestiços da raça Anglonubiana, com idade média inicial de oito meses e peso corporal de $18 \pm$ $2,5 \mathrm{~kg}$, que foram pesados após jejum de $16 \mathrm{~h}$ antes do início do período experimental para posterior distribuição nos tratamentos, segundo delineamento de blocos casualizados, com quatro tratamentos (níveis de suplementação) e oito repetições (caprinos).

A pesquisa teve duração de 101 dias, com 17 dias de adaptação às condições experimentais e 84 dias de coletas de dados, com estes subdivididos em quatro períodos de 21 dias. Os caprinos foram mantidos em regime de pastejo com lotação contínua em área experimental de 37 hectares, apresentando vegetação de caatinga hiperxerófila do tipo arbustivoarbóreo-denso, tendo acesso à pastagem das $7 \mathrm{~h}$ às $16 \mathrm{~h}$, quando eram recolhidos para o galpão experimental e alojados em baias individuais para receberem a suplementação alimentar.

Ressalta-se que a palma foi triturada momentos antes do fornecimento aos animais e homogeneizada à pré-mistura de concentrados energético-proteico.

O desempenho foi acompanhado por meio de pesagens realizadas em intervalos de sete dias, precedida de jejum de $16 \mathrm{~h}$, antes dos animais terem acesso ao pasto de caatinga. Os dados de ganho de peso foram utilizados ainda para o ajuste semanal do fornecimento do suplemento alimentar, com base no peso corporal.

Ao término dos 101 dias do período experimental os animais foram abatidos, sendo antes pesados para determinação do peso corporal sem jejum (PC), e posteriormente submetidos a jejum de sólidos (18h). Decorrido este período, foram novamente pesados para a obtenção do peso corporal ao abate (PCA), utilizado para o cálculo da perda de peso decorrente do jejum (PJ), pela fórmula: PJ $(\%)=(\mathrm{PC}-\mathrm{PCA}) \times 100 / \mathrm{PC}$. $\mathrm{O}$ abate foi realizado mediante atordoamento seguido de sangria por quatro minutos, com corte da carótida e jugular, segundo Instrução Normativa n'3 de 17 de janeiro de 2000 vigente (Brasil, 2000). Após o abate, esfola e evisceração, retiraram-se a cabeça e as patas para registro do peso da carcaça quente (PCQ), utilizando para o cálculo do rendimento de carcaça quente ou comercial (RCQ\%) pela fórmula: RCQ $(\%)=\mathrm{PCQ} / \mathrm{PCA} \times 100$. 
Rev. Bras. Saúde Prod. Anim., Salvador, v.15, n.3, p.705-716 jul./set., 2014 http://www.rbspa.ufba.br ISSN 15199940

Tabela 1. Ingredientes, composição centesimal e bromatológica do suplemento alimentar

\begin{tabular}{|c|c|c|c|c|c|}
\hline \multirow{2}{*}{ Nutriente } & \multicolumn{5}{|c|}{ Ingrediente } \\
\hline & Palma & Milho & Farelo de & Farelo de & Caroço de \\
\hline \multicolumn{5}{|l|}{$\%$ na MS } & 91,31 \\
\hline Matéria orgânica & 86,08 & 98,03 & 94,44 & 93,27 & 96,30 \\
\hline Cinzas & 13,92 & 1,97 & 5,56 & 6,73 & 3,70 \\
\hline Proteína bruta & 2,98 & 11,01 & 19,73 & 52,28 & 24,37 \\
\hline Extrato etéreo & 0,78 & 6,28 & 4,07 & 3,79 & 16,84 \\
\hline Carboidratos totais ${ }^{\mathrm{a}}$ & 82,68 & 80,74 & 70,64 & 37,20 & 55,09 \\
\hline Fibra em detergente neutro & 18,4 & 22,74 & 40,67 & 21,72 & 49,35 \\
\hline Fibra em detergente ácido & 8,84 & 2,67 & 11,76 & 6,52 & 11,76 \\
\hline \multicolumn{3}{|l|}{ Ingrediente } & \multicolumn{3}{|c|}{ Composição centesimal } \\
\hline \multicolumn{3}{|l|}{ Palma miúda } & \multicolumn{3}{|c|}{50,00} \\
\hline \multicolumn{3}{|l|}{ Milho triturado } & \multicolumn{3}{|c|}{16,14} \\
\hline \multicolumn{3}{|l|}{ Farelo de trigo } & \multicolumn{3}{|c|}{9,94} \\
\hline \multicolumn{3}{|l|}{ Caroço de algodão } & \multicolumn{3}{|c|}{17,22} \\
\hline \multicolumn{3}{|l|}{ Farelo de soja } & \multicolumn{3}{|c|}{5,70} \\
\hline \multicolumn{3}{|l|}{ Núcleo mineral vitamínico ${ }^{\mathrm{b}}$} & \multicolumn{3}{|c|}{1,00} \\
\hline \multicolumn{3}{|l|}{ Nutriente } & \multicolumn{3}{|c|}{ Composição bromatológica } \\
\hline \multicolumn{3}{|l|}{$\begin{array}{l}\text { Matéria Seca (MS), \% } \\
\% \text { na MS }\end{array}$} & \multicolumn{3}{|c|}{21,85} \\
\hline \multicolumn{3}{|l|}{ Matéria orgânica } & \multicolumn{3}{|c|}{89,18} \\
\hline \multicolumn{3}{|l|}{ Cinza } & \multicolumn{3}{|c|}{10,82} \\
\hline \multicolumn{3}{|l|}{ Proteína bruta } & \multicolumn{3}{|c|}{12,57} \\
\hline \multicolumn{3}{|l|}{ Extrato etéreo } & \multicolumn{3}{|c|}{5,79} \\
\hline \multicolumn{3}{|l|}{ Carboidratos totais ${ }^{\mathrm{a}}$} & \multicolumn{3}{|c|}{71,07} \\
\hline Fibra em detergente neutro & para cinza & & & 24,04 & \\
\hline Fibra em detergente ácido & & & & 10,87 & \\
\hline Hemicelulose & & & & 13,21 & \\
\hline Celulose & & & & 9,49 & \\
\hline Lignina & & & & 0,57 & \\
\hline Digestibilidade in vitro da $\mathrm{N}$ & & & & 78,56 & \\
\hline
\end{tabular}

${ }^{\mathrm{a}}$ Calculados segundo Sniffen et al. (1992); ${ }^{\mathrm{b}}$ Caprinofós ${ }^{\circledR}$ (Tortuga, Brasil).

O peso de corpo vazio (PCVZ) foi calculado pela fórmula: $\mathrm{PCVZ}=\mathrm{PCA}-$ (conteúdos do trato gastrointestinal, da bexiga e da vesícula biliar), que foi utilizado juntamente com PCQ para determinação do rendimento verdadeiro $(\mathrm{RV} \%)$, pela fórmula: RV $(\%)=$ (PCQ/PCVZ) x 100.

Após a obtenção do PCQ, as carcaças foram imediatamente resfriadas por $24 \mathrm{~h}$ a $4^{\circ} \mathrm{C}$ em câmara frigorífica e, ao final deste período, pesadas para a obtenção do peso da carcaça fria (PCF), utilizado para o cálculo do rendimento de carcaça fria (RCF\%) e perda de peso da carcaça decorrente do resfriamento (PR\%) pelas fórmulas: $\mathrm{RCF}(\%)=\mathrm{PCF} / \mathrm{PCA} \times 100 \mathrm{e}$ $\mathrm{PR}(\%)=(\mathrm{PCQ}-\mathrm{PCF}) / \mathrm{PCQ} \times 100$, respectivamente.

Após a retirada da cauda e do timo, as carcaças foram seccionadas longitudinalmente, obtendo-se as meias carcaças esquerda e direita que foram subdivididas em pescoço, paleta, costilhar, lombo, pernil e costela inferior ou serrote, segundo a metodologia de 
Cezar \& Sousa (2007), que foram pesados individualmente, para o cálculo de suas proporções em relação ao reconstituído da meia-carcaça esquerda. Posteriormente, pernil esquerdo foi embalado a vácuo e armazenado $\mathrm{a}-20^{\circ} \mathrm{C}$ para posterior determinação da composição tecidual.

As dissecações dos pernis foram realizadas em ambiente climatizado, após descongelamento sob refrigeração a $4^{\circ} \mathrm{C}$ por $18 \mathrm{~h}$, sendo posteriormente pesados e dissecados em: tecido adiposo (subcutâneo e intermuscular), muscular, ósseo e outros tecidos (tecido conjuntivo, tendões, glândulas, fáscias, nervos e vasos), determinando-se em seguida as relações músculo: osso e músculo:gordura, segundo Cezar \& Sousa (2007). O peso dos cinco principais músculos (g) que envolvem o fêmur (PM5), Biceps femuris, Semitendinosus, Adductor, Semimembranosus e Quadriceps femuris, foi utilizado juntamente com o comprimento de fêmur $(\mathrm{CF}, \mathrm{cm})$ para o cálculo do índice de musculosidade da perna (IMP), pela fórmula proposta por Purchas et al. (1991):

$$
I M P=\frac{\sqrt{\frac{P M 5}{C F}}}{C} .
$$

Adotou-se delineamento em blocos casualizados, com quatro tratamentos (Níveis de suplementação), oito repetições (Caprinos) e quatro blocos (Intevalos de pesos corporais, 14-15; 1617; 18-19; e 20-21kg), segundo modelo matemático: $\gamma_{\mathrm{ij}}=\mu+\tau_{\mathrm{i}}+\beta_{\mathrm{j}}+\varepsilon_{\mathrm{ij}}$, em que $\gamma_{i j}=$ valor observado na parcela que recebeu o i-ésimo tratamento no j-ésimo bloco; $\mu=$ média geral; $\tau_{\mathrm{i}}=\mathrm{i}$-ésimo efeito de tratamento; $\beta_{\mathrm{j}}=\mathrm{j}$-ésimo efeito de bloco; e $\varepsilon_{\mathrm{ij}}=$ erro aleatório associado ao iésimo tratamento e j-ésimo bloco.

Os dados foram analisados segundo o procedimento PROC MEANS do logiciário estatístico SAS
(STATISTICAL ANALYSIS SYSTEM, 2001), com realização de estatísticas descritivas para média, desvio-padrão e coeficiente de variação. Foram realizadas ainda análises de regressão linear e quadrática por meio do PROC GLM, segundo método de quadrados mínimos, adotando-se para a seleção dos modelos, a significância de 0,05 , bem como o coeficiente de regressão dos mesmos. As análises de correlação foram realizadas segundo procedimento PROC CORR, adotando-se o nível de significância de 0,05 .

\section{RESULTADOS E DISCUSSÃO}

Os parâmetros peso corporal sem jejum (PC), peso corporal ao abate (PCA), peso de carcaça quente (PCQ), peso de carcaça fria $(\mathrm{PCF})$, rendimento de carcaça quente (RCQ), rendimento de carcaça fria (RCF) e peso de corpo vazio (PCVZ) foram influenciados $(\mathrm{P}<0,05)$ pelos níveis de suplementação alimentar, com aumento linear de acordo com a elevação dos níveis de suplementação (Tabela 2).

A perda decorrente do jejum (PPJ) não foi influenciada $(\mathrm{P}>0,05)$ pelos níveis de suplementação alimentar (Tabela 2), com média $5,31 \%$. Desta forma, podese inferir que as elevações lineares nos parâmetros PCA, PCQ, PCF, RCQ e $\mathrm{RCF}$, não sofreram influência do jejum alimentar pré-abate, bem como do consumo de suplemento, caracterizando assim, incrementos decorrentes exclusivamente da suplementação alimentar.

Cezar \& Sousa (2007) enfatizam que o efeito do jejum sobre a perda de peso corporal e, portanto, sobre o rendimento de carcaça depende do tipo de alimento consumido pelo animal, onde, animais alimentados com dietas fibrosas e de baixa digestibilidade tendem a 
apresentar menor PPJ em relação àqueles alimentados com menores teores de fibras, resultando em elevados rendimento de carcaça, mesmo que submetidos a igual tempo de jejum.

A ausência de efeito da suplementação sobre a PPJ resultou em certa uniformidade entre o comportamento dos parâmetros de PC e PCA, que apresentaram efeito linear positivo $(\mathrm{P}<0,05)$, com elevação de 3,50 e $2,60 \mathrm{~kg}$, respectivamente, por unidade percentual do nível de suplementação.

Tabela 2. Médias e equações de regressão para as características da carcaça de caprinos mestiços Anglonubiana terminados em pastagem de caatinga recebendo suplementação alimentar

\begin{tabular}{|c|c|c|c|c|c|c|}
\hline \multirow{2}{*}{ Parâmetro } & \multicolumn{4}{|c|}{ Nível de suplementação (\%PC) } & \multirow{2}{*}{$\begin{array}{l}\text { Equação de } \\
\text { regressão }\end{array}$} & \multirow{2}{*}{$\mathrm{CV}(\%)$} \\
\hline & 0 & 0,4 & 0,8 & 1,2 & & \\
\hline PCI (kg) & 19,21 & 18,69 & 18,51 & 18,61 & - & - \\
\hline $\mathrm{PC}(\mathrm{kg})$ & 19,49 & 20,56 & 21,57 & 23,69 & 1 & 12,89 \\
\hline PCA $(\mathrm{kg})$ & 18,93 & 19,50 & 20,11 & 22,19 & 2 & 13,66 \\
\hline PCQ (kg) & 7,30 & 7,98 & 8,46 & 9,58 & 3 & 13,51 \\
\hline $\mathrm{PCF}(\mathrm{kg})$ & 6,93 & 7,59 & 8,05 & 9,13 & 4 & 15,74 \\
\hline PPJ (\%) & 5,34 & 4,45 & 5,68 & 5,76 & $\hat{\mathrm{Y}}=5,31, \mathrm{~ns}^{\mathrm{a}}$ & 21,91 \\
\hline $\operatorname{RCQ}(\%)$ & 39,60 & 40,37 & 41,39 & 42,50 & 5 & 5,13 \\
\hline $\mathrm{RCF}(\%)$ & 37,60 & 38,88 & 39,39 & 40,53 & 6 & 5,18 \\
\hline $\mathrm{PR}(\%)$ & 5,02 & 4,94 & 4,83 & 4,66 & $\hat{\mathrm{Y}}=4,86, \mathrm{~ns}$ & 7,50 \\
\hline PCVZ (kg) & 14,18 & 15,13 & 16,07 & 18,40 & 7 & 14,64 \\
\hline $\mathrm{RV}(\%)$ & 51,75 & 52,62 & 52,49 & 52,03 & $\hat{\mathrm{Y}}=52,23, \mathrm{~ns}$ & 4,38 \\
\hline Espessura de gordura & 0,84 & 0,75 & 0,66 & 0,75 & $\hat{\mathrm{Y}}=0,75, \mathrm{~ns}$ & 15,17 \\
\hline \multicolumn{7}{|c|}{$\begin{array}{ll}{ }^{2} \text { Não significativo, } P>0,05 & \\
{ }^{1} \hat{Y}=19,1898+3,5033 X, R^{2}=0,23 ; P<0,015 & { }^{5} \hat{Y}=39,5107+2,4268 X, R^{2}=0,22 ; P<0,011 \\
{ }^{2} \hat{Y}=18,6241+2,5961 X, R^{2}=0,70 ; P<0,026 & { }^{6} \hat{Y}=37,5106+2,4425 X, R^{2}=0,24 ; P<0,008 \\
{ }^{3} \hat{Y}=7,1795+1,6987 X, R^{2}=0,34 ; P<0,001 & { }^{7} \hat{Y}=13,9094+3,3945 X, R^{2}=0,31 ; P<0,002 \\
{ }^{4} \hat{Y}=6,8675+1,7661 X, R^{2}=0,30 ; P<0,003 & \end{array}$} \\
\hline
\end{tabular}

O PCQ e PCF apresentaram elevação linear $(\mathrm{P}<0,05)$ com acréscimos de 1,70 e $1,77 \mathrm{~kg}$, respectivamente, em função dos níveis de suplementação, sendo estes valores resultantes do maior consumo do suplemento alimentar, que proporcionou maior aporte de nutrientes para o desenvolvimento dos animais.

Os resultados para PCQ e PCF enquadram-se no perfil de carcaças leves atualmente mais demandadas por mercados consumidores exigentes, localizados em grandes centros urbanos, pelo fato destas serem originárias de animais mais jovens. Apesar destes resultados, atualmente não esta disponível na legislação brasileira uma regulamentação para classificação e tipificação de carcaça caprina, o que compromete a padronização das carcaças comercializadas.

Em adição, na região Nordeste este padrão ainda precisa ser melhorado, pois conforme comentam Mattos et al. (2006), nesta região o abate ocorre predominantemente quando os animais 
apresentam 25 a $30 \mathrm{~kg}$, resultando em carcaças com 12 a $13 \mathrm{~kg}$, procedentes, contudo, de animais com mais de um ano de idade.

A suplementação alimentar ocasionou efeito linear positivo $(\mathrm{P}<0,05)$ sobre o RCQ e RCF, com elevação de 2,43 e $2,44 \mathrm{~kg}$, respectivamente, por unidade percentual de suplementação alimentar (Tabela 2). Os rendimentos de carcaça nesta pesquisa estiveram próximo aos intervalos aos obtidos por Oliveira et al. (2008), 43,3 a 45,6 para RCQ e 42,3 a 44,7\% para RCF, em caprinos mestiços $3 / 4$ Anglonubiana $x$ 1/4 SRD, 3/4 Boer $x$ SDR e SRD, terminados em caatinga raleada, recebendo suplementação alimentar.

O rendimento de carcaça é uma característica diretamente relacionada à produção de carne, contudo, variações são aceitáveis, pois estão função de fatores intrínsecos ao próprio animal (genótipo, sexo, peso, idade) e/ou extrínsecos (alimentação, manejo, tipo de jejum).

$\mathrm{O}$ incremento no RCQ e RCF caracteriza reflexo positivo da suplementação alimentar, que permitiu a correção da carência em relação ao consumo de matéria seca e matéria orgânica potencialmente digestível, em função dos níveis de suplementação alimentar. Fato que contribuiu para maior aporte de nutrientes disponíveis para o metabolismo animal, culminando com maior deposição de tecido muscular e ósseo em relação ao trato gastrointestinal.

A perda por resfriamento (PR) não foi influenciada $(\mathrm{P}>0,05)$ pelos níveis de suplementação alimentar, com média $4,86 \%$. Este resultado pode estar diretamente relacionado à ausência de efeito $(\mathrm{P}>0,05)$ para a espessura de gordura, em média $0,75 \mathrm{~mm}$. Estes parâmetros apresentam grande relação, uma vez que carcaças com maior deposição de gordura tendem a apresentar menor perda por resfriamento devido ao efeito de proteção da gordura contra a perda de água, durante o processo de resfriamento em câmara fria.

A reduzida deposição de gordura subcutânea é característica da espécie caprina, apresentando ainda influência do manejo alimentar. Nas condições desta pesquisa, a terminação em pastagem de caatinga resultou em carcaças com reduzida adiposidade. Assim, a espessura de gordura aqui obtida, inferior a $1,0 \mathrm{~mm}$ entre a 12 e $13^{\mathrm{a}}$ vértebras torácicas, permite classificar as carcaças segundo Silva Sobrinho \& Gonzaga Neto (2010) como magras. A quantidade de gordura e a distribuição subcutânea apresentam-se como um importante componente da carcaça, e assim, respeitando-se as exigências particulares dos mercados compradores, excesso ou falta de gordura são indesejáveis.

Os cortes comerciais foram influenciados $(\mathrm{P}<0,05)$ pelos níveis da suplementação alimentar, exibindo aumento linear de acordo com a elevação dos mesmos. A exceção foi o rendimento do pescoço (média de $0,400 \mathrm{~kg}$ ) que não foi influenciado $(\mathrm{P}>0,05)$, sendo este resultado benéfico, uma vez que o pescoço é caracterizado como um corte de baixo valor comercial (Tabela 3 ).

Apesar do efeito positivo do nível de suplementação alimentar sobre o peso dos cortes comerciais, a avaliação em termos percentuais não foi influenciada ( $\mathrm{P}>0,05 \%$ ), com médias 10,$17 ; 21,19$; 16,$23 ; 11,02 ; 7,30$ e $34,08 \%$ para o pescoço, paleta, costilhar, serrote, lombo e pernil, respectivamente (Tabela $3)$.

Os pesos dos cortes, entre o menor e maior nível de suplementação, variaram de 0,74 a $0,93 \mathrm{~kg}$ para a paleta, 0,57 a $0,73 \mathrm{~kg}$ para o costilhar, e 0,25 a 0,33 para o lombo, com aumentos 
lineares $(\mathrm{P}<0,05)$ de 0,$153 ; 0,126 \mathrm{e}$ $0,061 \mathrm{~kg}$, respectivamente, tendo este desenvolvimento acompanhado a variação do peso corporal final, entre o menor $(18,93 \mathrm{~kg})$ e maior $(22,19 \mathrm{~kg})$ nível de suplementação.

O corte do pernil apresentou variação de peso de 1,18 a $1,53 \mathrm{~kg}$, entre o menor e maior nível de suplementação alimentar, respectivamente, resultante de uma elevação linear $(\mathrm{P}<0,05)$ de $0,290 \mathrm{~kg}$ para cada unidade percentual do nível de suplementação. Apesar desta elevação, o rendimento em termos percentuais para o referido corte não foi influenciado $(\mathrm{P}>0,05)$, onde este representou em média $34,08 \%$ da composição da meia carcaça.

Tabela 3. Médias e equações de regressão para o peso e rendimento dos cortes comerciais da carcaça de caprinos mestiços Anglonubiana terminados em pastagem de caatinga recebendo suplementação alimentar

\begin{tabular}{|c|c|c|c|c|c|c|}
\hline \multirow{2}{*}{ Corte $(\mathrm{kg})$} & \multicolumn{4}{|c|}{ Nível de suplementação (\%PC) } & \multirow{2}{*}{ Equação de regressão } & \multirow{2}{*}{$\mathrm{CV}(\%)$} \\
\hline & 0 & 0,4 & 0,8 & 1,2 & & \\
\hline $1 / 2$ Carcaça esquerda & 3,48 & 3,77 & 3,99 & 4,46 & 1 & 15,74 \\
\hline Pescoço & 0,38 & 0,37 & 0,39 & 0,46 & $\hat{\mathrm{Y}}=0,40, \mathrm{~ns}^{\mathrm{a}}$ & 19,79 \\
\hline Paleta & 0,74 & 0,80 & 0,86 & 0,93 & 2 & 16,17 \\
\hline Costilhar & 0,57 & 0,62 & 0,63 & 0,73 & 3 & 18,63 \\
\hline Serrote & 0,37 & 0,42 & 0,45 & 0,48 & 4 & 18,38 \\
\hline Lombo & 0,25 & 0,28 & 0,29 & 0,33 & 5 & 21,93 \\
\hline Pernil & 1,18 & 1,27 & 1,37 & 1,53 & 6 & 14,40 \\
\hline \multicolumn{7}{|l|}{ Rendimento (\%) } \\
\hline Pescoço & 10,89 & 9,78 & 9,76 & 10,26 & $\hat{\mathrm{Y}}=10,17, \mathrm{~ns}$ & 11,29 \\
\hline Paleta & 21,26 & 21,31 & 21,44 & 20,77 & $\hat{\mathrm{Y}}=21,19, \mathrm{~ns}$ & 3,95 \\
\hline Costilhar & 16,31 & 16,44 & 15,83 & 16,34 & $\hat{\mathrm{Y}}=16,23, \mathrm{~ns}$ & 7,15 \\
\hline Serrote & 10,57 & 11,19 & 11,40 & 10,91 & $\hat{\mathrm{Y}}=11,02, \mathrm{~ns}$ & 8,69 \\
\hline Lombo & 7,15 & 7,50 & 7,21 & 7,34 & $\hat{\mathrm{Y}}=7,30, \mathrm{~ns}$ & 11,92 \\
\hline Pernil & 33,82 & 33,79 & 34,36 & 34,38 & $\hat{\mathrm{Y}}=34,08, \mathrm{~ns}$ & 3,05 \\
\hline
\end{tabular}

${ }^{a}$ Não significativo, $\mathrm{P}>0,05 ; \mathrm{CV}=$ Coeficiente de variação.

$$
\begin{array}{ll}
{ }^{1} \hat{Y}=3,450+0,7886 X, R^{2}=0,26 ; P<0,006 & { }^{4} \hat{Y}=0,377+0,0932 X, R^{2}=0,23 ; P<0,01 \\
{ }^{2} \hat{Y}=0,739+0,1527 X, R^{2}=0,22 ; P<0,012 & { }^{5} \hat{Y}=0,250+0,0614 X, R^{2}=0,17 ; P<0,029 \\
{ }^{3} \hat{Y}=0,562+0,1263 X, R^{2}=0,20 ; P<0,018 & { }^{6} \hat{Y}=1,161+0,2902 X, R^{2}=0,33 ; P<0,001
\end{array}
$$

Os resultados verificados para as porcentagens dos cortes em relação à meia carcaça reforçam a lei da harmonia anatômica, onde as regiões corporais em geral estão apresentadas em proporções semelhantes, independentemente da conformação dos genótipos considerados, o que justifica a ausência de efeito para as avaliações em termos percentuais.

O valor comercial de uma carcaça é avaliado pela proporção dos seus cortes mais nobres, sendo então as de maior valor comercial aquelas que apresentam maior participação da paleta, pernil e lombo. Nesta pesquisa, estes cortes representaram juntos $62,57 \%$ da meia carcaça, sendo próximo aos 63,3\%, encontrados por Yáñes et al. (2007) e aos e 59,56\% de Mattos et al. (2006).

A preferência dos consumidores por determinados cortes comerciais pode apresentar variação entre as regiões. 
Segundo Mattos et al. (2006), a região Nordeste as costelas são muito valorizadas pelo mercado consumidor, alcançando em muitas vezes valor de mercado semelhante ao quilograma do pernil. Desta forma, a soma das percentagens do costilhar e pernil foi de $50,31 \%$ nesta pesquisa, o que representa uma considerável fração da meia carcaça fria.

Os parâmetros de composição tecidual do pernil apresentaram efeito linear positivo $(\mathrm{P}<0,05)$, com elevação de 293,$59 ; 212,04 ; 28,29$ e $53,82 \mathrm{~g}$ por unidade percentual do nível de suplementação, para o pernil inteiro, músculo total, gordura total e osso, respectivamente, com exceção do peso absoluto dos outros tecidos que não foram influenciados $(\mathrm{P}>0,05)$, com média $75,88 \mathrm{~g}$.

O peso do pernil apresentou elevação de $30,67 \%$ entre os animais submetidos ao menor e maior nível de suplementação alimentar, indicando o efeito benéfico da suplementação. Esta prática adequou o nível nutricional a partir da correção das deficiências do pasto para patamares acima da mantença, permitindo $\mathrm{o}$ desenvolvimento dos tecidos. Este fato está diretamente relacionado ao maior consumo de nutrientes digestíveis totais (NDT) pelos animais suplementados com $1,2 \%$ do PC $(299,59 \mathrm{~g} / \mathrm{animal} / \mathrm{dia}$ de NDT) em relação aos não suplementados (101,48 g/animal/dia de NDT).

Verificou-se correlação positiva $(\mathrm{P}<0,05)$ entre o peso do pernil e os parâmetros, músculo total $(\mathrm{r}=0,99)$, gordura total $(\mathrm{r}=0,76) \mathrm{e}$ ossos $(r=0,91)$, sugerindo que $o$ desenvolvimento deste corte não esteve relacionado apenas à deposição de tecido muscular, confirmado ainda pela ausência de efeito $(\mathrm{P}>0,05)$ dos níveis de suplementação alimentar sobre as relações músculo:osso, músculo:gordura, e a musculosidade da perna (Tabela 4). Contudo, é notável a contribuição dos músculos quadríceps, semimembranoso, semitendinoso, bíceps e adutor, para a elevação do peso do pernil, uma vez que estes apresentaram elevação de 35,$16 ; 31,02 ; 16,02 ; 27,18$ e $14,02 \mathrm{~g}$, respectivamente, por unidade percentual de suplementação.

Nesta situação, os animais ainda se encontravam em fase de desenvolvimento corporal, permitindo equivalência entre o desenvolvimento dos tecidos, verificada pela deposição de músculo acompanhada do crescimento ósseo e da deposição de gordura.

A gordura total apresentou elevação ( $\mathrm{P}>0,05)$ de 28,29g em função dos níveis suplementação alimentar (Tabela 4), sugerindo que seu emprego em níveis mais elevados pode ter propiciado aumento do teor de energia metabolizável disponível para a síntese de triglicerídeos. Este comportamento é relatado por Gerrard \& Grant (2006), em que o aumento no volume dos adipócitos subcutâneos e intermusculares foi constatado em animais alimentados ad libitum, em relação ao grupo em mantença.

A suplementação alimentar não influenciou $(\mathrm{P}>0,05)$ os parâmetros de rendimento de músculo total, ossos, gordura total e outros tecidos, com médias 66,82; 22,62; 4,98 e 5,79\%, respectivamente (Tabela 5). Os valores de rendimento muscular e ósseo foram superiores aos verificados por Monte et al. (2007), 65,9 e 13,7\%, respectivamente, ao avaliarem a composição tecidual da carcaça de caprinos mestiços $1 / 2$ Anglonubiano x $1 / 2$ SRD e $1 / 2$ Boer x $1 / 2$ SRD terminados em regime de semiconfinamento em pasto nativo melhorado. Por outro lado, o rendimento de gordura total e outros tecidos foram inferiores aos descritos pelos mesmos, 7,9 e $12,3 \%$, respectivamente. 
Rev. Bras. Saúde Prod. Anim., Salvador, v.15, n.3, p.705-716 jul./set., 2014 http://www.rbspa.ufba.br ISSN 15199940

Tabela 5. Médias e equações de regressão para a composição tecidual do pernil de caprinos mestiços Anglonubiana terminados em pasto de caatinga recebendo suplementação alimentar

\begin{tabular}{|c|c|c|c|c|c|c|}
\hline \multirow{2}{*}{ Parâmetro } & \multicolumn{4}{|c|}{ Nível de suplementação (\%PC) } & \multirow{2}{*}{$\begin{array}{l}\text { Equação de } \\
\text { regressão }\end{array}$} & \multirow{2}{*}{$\begin{array}{l}\mathrm{CV} \\
(\%)\end{array}$} \\
\hline & 0 & 0,4 & 0,8 & 1,2 & & \\
\hline Pernil inteiro $(\mathrm{g})$ & 1171,00 & 1269,50 & 1366,21 & 1530,21 & 1 & 8,65 \\
\hline Músculo total (g) & 756,14 & 842,43 & 903,93 & 1018,36 & 2 & 8,39 \\
\hline Quadríceps (g) & 152,43 & 164,71 & 172,29 & 196,79 & 3 & 7,03 \\
\hline Semimembranoso $(\mathrm{g})$ & 130,07 & 148,79 & 161,64 & 175,14 & 4 & 9,08 \\
\hline Semitendinoso (g) & 46,07 & 50,93 & 57,14 & 65,36 & 5 & 19,00 \\
\hline Biceps (g) & 85,07 & 97,36 & 104,71 & 118,86 & 6 & 13,66 \\
\hline Adutor (g) & 58,71 & 61,07 & 64,64 & 76,21 & 7 & 14,66 \\
\hline Outros músculos (g) & 283,79 & 319,57 & 343,50 & 386,00 & 8 & 9,31 \\
\hline Gordura total (g) & 56,21 & 51,93 & 69,50 & 88,07 & 9 & 22,83 \\
\hline Subcutânea (g) & 27,17 & 20,57 & 28,79 & 39,93 & 10 & 27,08 \\
\hline Intermuscular (g) & 32,93 & 31,36 & 40,71 & 48,14 & 11 & 25,60 \\
\hline Ossos $(\mathrm{g})$ & 268,14 & 281,29 & 300,71 & 333,43 & 12 & 11,11 \\
\hline Outros tecidos (g) & 68,28 & 80,36 & 79,00 & 75,89 & $\hat{\mathrm{Y}}=75,88, \mathrm{~ns}^{\mathrm{a}}$ & 30,27 \\
\hline Compri. fêmur $(\mathrm{cm})$ & 16,81 & 17,63 & 17,74 & 18,06 & 13 & 3,69 \\
\hline Músculo:osso & 2,86 & 3,00 & 3,00 & 3,05 & $\hat{\mathrm{Y}}=2,98, \mathrm{~ns}$ & 8,87 \\
\hline Músculo:gordura & 13,86 & 16,85 & 13,46 & 12,23 & $\hat{\mathrm{Y}}=14,1, \mathrm{~ns}$ & 23,00 \\
\hline Musculosidade & 0,32 & 0,31 & 0,31 & 0,33 & $\hat{\mathrm{Y}}=0,32, \mathrm{~ns}$ & 4,50 \\
\hline \multicolumn{7}{|l|}{ Rendimento $(\%)$} \\
\hline Músculo total & 66,28 & 67,07 & 66,75 & 67,16 & $\hat{\mathrm{Y}}=66,82, \mathrm{~ns}$ & 2,80 \\
\hline Ossos & 23,65 & 22,42 & 22,31 & 22,11 & $\hat{\mathrm{Y}}=22,62, \mathrm{~ns}$ & 6,80 \\
\hline Gordura total & 4,87 & 4,11 & 5,18 & 5,78 & $\hat{\mathrm{Y}}=4,98, \mathrm{~ns}$ & 21,18 \\
\hline Subcutânea & 2,30 & 1,61 & 2,19 & 2,63 & $\hat{\mathrm{Y}}=2,18, \mathrm{~ns}$ & 30,17 \\
\hline Intermuscular & 2,47 & 2,33 & 2,72 & 2,91 & $\hat{\mathrm{Y}}=2,61, \mathrm{~ns}$ & 25,60 \\
\hline Outros tecidos & 6,08 & 6,40 & 5,76 & 4,95 & $\hat{\mathrm{Y}}=5,79, \mathrm{~ns}$ & 27,08 \\
\hline
\end{tabular}

${ }^{\mathrm{a}} \mathrm{Não}$ significativo, $\mathrm{P}>0,05 ; \mathrm{CV}=$ Coeficiente de variação.

$\begin{array}{ll}{ }^{1} \hat{Y}=1158,08+293,59 X, R^{2}=0,79 ; P<0,01 & { }^{8} \hat{Y}=283,63+82,64 X, R^{2}=0,78 ; P<0,0005 \\ { }^{2} \hat{Y}=753,00+212,04 X, R^{2}=0,82 ; P<0,007 & { }^{9} \hat{Y}=49,46+28,29 X, R^{2}=0,59 ; P<0,001 \\ { }^{3} \hat{Y}=150,46+35,16 X, R^{2}=0,86 ; P<0,002 & { }^{10} \hat{Y}=26,48-21,37 X+27,56 X^{2}, R^{2}=0,56 ; P<0,01 \\ { }^{4} \hat{Y}=131,70+31,02 X, R^{2}=0,79 ; P<0,0009 & { }^{11} \hat{Y}=29,15+14,70 X, R^{2}=0,52 ; P<0,01 \\ { }^{5} \hat{Y}=45,26+16,02 X, R^{2}=0,55 ; P<0,005 & { }^{12} \hat{Y}=263,60+53,82 X, R^{2}=0,62, P<0,007 \\ { }^{6} \hat{Y}=85,19+27,18 X, R^{2}=0,69 ; P<0,003 & { }^{13} \hat{Y}=16,98+0,96 X, R^{2}=0,65 ; P<0,02\end{array}$

${ }^{7} \hat{Y}=56,75+14,02 X, R^{2}=0,63 ; P<0,01$

Estas diferenças podem ser explicadas, pelo fato da terminação dos animais desta pesquisa ter ocorrido em pastagem nativa de caatinga, que impunha grande deslocamento em busca de alimento, contribuindo assim para maior desenvolvimento muscular e ósseo, além de menor deposição de tecido adiposo.

A suplementação alimentar de caprinos mestiços da raça Anglonubiana terminados em pastagem de caatinga eleva os parâmetros quantitativos da carcaça, associado a incrementos no 
Rev. Bras. Saúde Prod. Anim., Salvador, v.15, n.3, p.705-716 jul./set., 2014 http://www.rbspa.ufba.br ISSN 15199940

tecido muscular, gordura total e ossos do pernil, recomendando-se emprego de $1,2 \%$ PC, com vistas a melhor acabamento para comercialização.

\section{REFERÊNCIAS}

BRASIL. Ministério da Agricultura. Instrução Normativa $\mathrm{n}^{\circ} .3$, de 07 de janeiro de 2000. Regulamento técnico de métodos de insensibilização para o abate humanitário de animais de açougue. S.D.A./M.A.A. Diário Oficial da União, Brasília, 24 de janeiro de 2000, Seção I, p.14-16. Disponível em: < http://extranet.agricultura.gov.br/sislegis/ action/detalhaAto.do?method=consultar LegislacaoFederal> Acesso em: 1 jun. 2010.

CARVALHO JÚNIOR, A.M.; PEREIRA FILHO, J.M.; SILVA, R.M.; CEZAR, M.F.; SILVA, A.M.A.; SILVA, A.L.N. Efeito da suplementação nas características de carcaça e dos componentes não-carcaça de caprinos $\mathrm{F} 1$ Boer x SRD terminados em pastagem nativa. Revista Brasileira de Zootecnia, v.38, n.7, p.1301-1308, 2009.

CEZAR, M.F.; SOUSA, W.H. Carcaças ovinas e caprinas: obtenção, avaliação e classificação. Uberaba: Agropecuária Tropical, 2007. 147p.

GERRARD, D.E.; GRANT, A.L. Principles of animal growth \& development. Dubuque, Iowa: Kendall/Hunt Publishing Company, 2006. 264p.

INSTITUTO BRASILEIRO DE GEOGRAFIA E ESTATÍSTICA IBGE. Pesquisa Pecuária Municipal, Rio de Janeiro, v.39, p.1-63, 2011. Disponível em: <ftp://ftp.ibge.gov.br/Producao_Pecuaria
/Producao_da_Pecuaria_Municipal/2011 /tabelas_pdf/tab04.pdf>. Acesso em: 19 jul. 2014.

\section{LABORATÓRIO DE METEOROLOGIA DE PERNAMBUCO - LAMEPE. \\ Climatologia. Disponível em: <http://www.itep.br/LAMEPE.asp $>$. Acesso em: 20 jul. 2011.}

LISBOA, A.C.C.; FURTADO, D.A.; MEDEIROS, A.N.; COSTA, R.G.; QUEIROGA, R.C.R.E.; BARRETO, L.M.G.; PAULO, J.L.A. Avaliação da qualidade da carne de cabritos nativos terminados com dietas contendo feno de Maniçoba. Revista Brasileira de Saúde e Produção Animal [online], v.11, n.4, p.1046-1055, 2010.

MATTOS, C.W.; CARVALHO, F.F.R.; DUTRA, W.M.; VÉRAS, A.S.C.; BATISTA, A.M.V.; ALVES, K.S.; RIBEIRO, V.L.; SILVA, M.J.M.S.; MEDEIROS, G.R.; VASCONCELOS, R.M.J.; ARAÚJO, A.O.; MIRANDA, S.B. Características de carcaça e dos componentes não-carcaça de cabritos Moxotó e Canindé submetidos a dois níveis de alimentação. Revista Brasileira de Zootecnia, v.35, n.5, p.2125-2134, 2006.

MONTE, A.L.S.; SELAIVE-

VILLARROEL, A.B.; PÉREZ, J.R.O.; ZAPATA, J.F.F.; BESERRA, F.J.; OLIVEIRA, A.N. Rendimento de cortes comerciais e composição tecidual da carcaça de cabritos mestiços. Revista Brasileira de Zootecnia, v.36, n.6, p.2127-2133, 2007. Supl.

NATIONAL RESEARCH COUNCIL (NRC). Nutrient requirements of small ruminants: sheep, goats, cervids, and new world camelids. Washington, D.C.: National Academy Press, 2007. 362p. 
OLIVEIRA, A.N.; SELAIVE-

VILLARROEL, A.B.; MONTE, A.L.S.; COSTA, R.G.; COSTA, L.B.A.

Características da carcaça de caprinos mestiços Anglo-Nubiano, Boer e sem padrão racial definido. Ciência Rural, v.38, n.4, p.1073-1077, 2008.

PURCHAS, R.W.; DAVIES, A.S.; ABDULLAH, A.Y. An objective measure of muscularity: changes with animal growth and differences between genetic lines of Southdown Sheep.

Meat Science, v.30, p.81-94, 1991.

SANTOS, G.R.A.; BATISTA, A.M.V.; GUIM, A.; SANTOS, M.V.F.; MATOS, D.S.; SANTORO, K.R.

Composição química e degradabilidade in situ da ração em ovinos em área de caatinga no sertão de Pernambuco.

Revista Brasileira de Zootecnia, v.38, n.2, p.384-391, 2009.

SILVA SOBRINHO, A.G.; GONZAGA NETO, S. Produção de carne caprina e cortes da carcaça. Disponível em: $<$ http://www.capritec.com.br/pdf/produ cao_carnecaprina.PD>. Acesso em: 20 maio 2010.
SNIFFEN, C.J.; O'CONNOR, J.D.; VAN SOEST, P.J.; FOX, D.G.;

RUSSELL, J.B. A net carbohydrate and protein system for evaluating cattle diets: II Carbohydrate and protein availability. Journal of Animal Science, v.70, p.3562-3577, 1992.

STATISTICAL ANALYSIS SYSTEM. SAS/STAT User's Guide. Version 9.3. Cary, NC: SAS Institute, 2011.

YÁÑEZ, E.A.; RESENDE, K.T.; FERREIRA, A.C.; MEDEIROS, A.N. ARTONI, S.M.B. Efects of feed restriction on yield, retail cuts and tissue composition of carcass of Saanen kids.

Revista Brasileira de Zootecnia, v.36, n.3, p.666-673, 2007.

Data de recebimento: 15/07/2013

Data de aprovação: 23/09/2014 